\title{
Stability Mechanism and Repair Method of U-Shaped Steel Reverse Arch Support in Soft Floor Roadway
}

\author{
Chao Wang $\mathbb{D}^{1,2}$ Xiaoyi Chen, ${ }^{3}$ Jiandong Zhang, ${ }^{3}$ and Yongping $\mathrm{Wu}^{2,4}$ \\ ${ }^{1}$ School of Mining and Coal Engineering, Inner Mongolia University of Science and Technology, Baotou 014010, China \\ ${ }^{2}$ School of Energy Sources, Xi'an University of Science and Technology, Shaanxi, Xi'an 710054, China \\ ${ }^{3}$ Institute of Mining Engineering, Inner Mongolia University of Science and Technology, Baotou 014010, China \\ ${ }^{4}$ Key Laboratory of Western Mine Exploitation and Hazard Prevention Ministry of Education, Shaanxi, Xi'an 710054, China \\ Correspondence should be addressed to Chao Wang; wangchao2006@imust.edu.cn
}

Received 19 June 2020; Revised 15 August 2020; Accepted 28 August 2020; Published 15 September 2020

Academic Editor: Fengqiang Gong

Copyright $\odot 2020$ Chao Wang et al. This is an open access article distributed under the Creative Commons Attribution License, which permits unrestricted use, distribution, and reproduction in any medium, provided the original work is properly cited.

\begin{abstract}
This paper is aimed at the inverted arch support instability of track roadway with mining level $+1100 \mathrm{~m}$ in Liuyuanzi Coal Mine. By means of field investigation, theoretical analysis, numerical calculation, and engineering practice, the instability reasons of inverted arch structure are expounded, the mechanical mechanism of instability of inverted arch structure is revealed, and the "sliding-rotating beam" for the instability of inverted arch structure is put forward. Based on Fenner's formula and mechanics principle, the equilibrium equation of "sliding-rotating beam" is given. The results show the following: Firstly, the insufficient stiffness at the joint of the inverted arch structure and the U-shaped steel support on the floor is the key reason for the floor instability. Secondly, when the action stress of the "sliding-rotating beam" is less than the critical value, three kinds of instability modes of the inverted arch structure may occur, that is, sliding upward, rotating upward, or sliding-rotating upward. Each instability criterion and critical value are also different. Considering the axisymmetric condition, the critical value calculation formula of the three modes can be simplified into one formula. Thirdly, the equivalent friction factor restricts the stability of the "sliding-rotating beam," and there is a "breaking point." The relationship between the equivalent friction factor and the action stress of the "sliding-rotating beam" is "class hyperbola." When the equivalent friction factor is greater than the "breaking point value," the "sliding-rotating beam" may remain stable. Moreover, with the increase of equivalent friction factor, the action stress required for the stability of the "sliding-rotating beam" is smaller, and it tends to be more stable. The breaking point value of equivalent friction factor is 18.6. Finally, 36U-shaped steel round frame with bolt-mesh-shotcrete-combined support is applied to improve the equivalent friction factor and the foot stiffness of U-shaped support in roadway. After two months of on-site implementation, the floor heave was reduced by $69.1 \%$. In conclusion, the theoretical analysis is correct and the control method is effective.
\end{abstract}

\section{Introduction}

Floor heave is one of the focuses concerned by scholars at home and abroad [1-7]. A series of dynamic phenomena $[8-11]$ such as roadway instability and floor water inrush are caused by floor heave, which not only affect mine ventilation, transportation, and pedestrians but also increase a lot of maintenance workload and mining costs $[12,13]$.

Due to the complexity of roadway occurrence environment, scholars have different opinions on the mechanism of roadway floor heave [14-17]. According to different floor heave mechanism, the control technology is also different [11, 18-21]. Mo [22] introduced some of the main floor heave events in the development of the Glencore Bulga Underground plant. The previously mentioned study indicates that the high horizontal stress of the roadway surrounding rocks and certain types of floor lithology configuration are the reasons for the failures of floor strata. Malkowski and Ostrowski [23] carried out the research of numerical modeling based on convergence monitoring records. The convergence measurements were carried out on three stations in a selected main gate in a coal mine from 
Upper Silesia Coal Basin near Jastrzebie-Zdroj. The width, the height, and the heave of the floor of the gate were measured. The authors highlight that, during the measurements period, the horizontal stress was 1.45 to 1.61 times greater than the concurrent vertical stress. The so high horizontal stress causes heave of unsupported gallery floor, which is commonly observed in the mines in Silesia. Mo et al. [24] studied especially the buckling failure mechanism in the floor and relevant analysis techniques on the coal mine floor. This paper introduces a new floor classification system, the Coal Mine Floor Rating, based on the underlying failure mechanisms. The new floor mass rating system quantifies the stability of floor strata by considering two main factors: uniaxial compressive strength and discontinuity spacing of the floor units. The floor heave and nonfloor heave cases are determined depending on the Coal Mine Floor Rating and the Horizontal Stress Rating. Lai et al. [25] studied the mechanism of roadway floor heave by field geological investigation, theoretical analysis, and numerical simulation. They thought that the surrounding rock of the roadway presents asymmetrical shrinkage under the original support condition, and it is the extrusion flow type floor heave. The bottom without support and influence of mining are the important causes of floor heave. Jia et al. [26] analyzed the stress environment, deformation, and failure characteristics of mining roadway in the fully mechanized caving face. The results revealed that the intrinsic cause of the large asymmetrical floor deformation in the mining roadway is the asymmetrical phenomenon of the surrounding rock's stress environment caused by mining. This also results in the nonuniform distribution of the mining roadway floor's plastic zone. Zhang et al. [27] analyzed the deformation and failure characteristics of the mining roadway's floor and elucidated the floor heave mechanisms of shallow bulging and deep sinking. Moreover, the displacement law of the floor rock at different depths was further analyzed, and the characteristics of "two dots and three areas" of the floor heave were determined. Kang et al. [28] analyzed the influence of mining and side pressure coefficient on the roadway floor heave. The relationships between the thickness of the soft rock stratum and the mechanical properties of the surrounding rock and floor heave were analyzed. Qin et al. [29] proposed and applied a reinforcement scheme for deep dynamic soft rock roadway. The results indicate the following: by increasing the supporting strength of the internal bearing structure, cohesion, and internal friction angle of the surrounding rock and by reducing the influence of mining, making the external bearing structure close to the roadway, and reducing the thickness of the bearing structure, the bearing capacity of the shallow surrounding rock in the roadway can be improved. Peng et al. [30] designed a U-type steel inverted arch and bolts support scheme to control the floor heave of the roadway. After calculation through the mechanical model of the inverted arch, its bearing capacity is $0.56 \mathrm{MPa}$. Through comparison and analysis of various supporting schemes, the "U-shaped steel + inverted arch + pouring concrete + backwall grouting" technology was selected, and the engineering practice showed that the supporting scheme can effectively improve surrounding rock stability. Shreedharan and Kulatilake [31] presented stability studies on two tunnels, a horseshoeshaped tunnel and an inverted arch-shaped tunnel, in a deep coal mine in China, performed using the 3DEC distinct element code. They illustrated the importance of incorporating stress relaxation before support installation through the increased support factor of safety and reduced grout failures. Finally, a comparison between the two differently shaped tunnels established that the inverted arch-shaped tunnel may be more efficient in reducing roof sag and floor heave for the existing geo-mining conditions. Chun et al. [32] designed a yielding inverted arch of composite structures to control serious floor heave of tunnel. They studied constitution of the inverted arch to present mechanism of the composite structure to restrain floor heave. By field trial of the yielding inverted arch with composite structures, it is an effective method to control floor heave, and its important function is to absorb main elastic deformation coming from bottom strata.

The above-mentioned scholars have done a lot of successful research and application on the mechanism and control of floor heave. Because of the complex and changeable environment of coal mine roadway or the fact that the key points of floor heave control are different, the researches on the mechanism of floor instability under inverted arch support are relatively few or only a part of the influencing factors are studied. Therefore, further study was needed to solve the instability and control of the antiarch support of the roadway with mining level $+1100 \mathrm{~m}$ in Liuyuanzi Coal Mine, especially the failure mechanism of the roadway floor under the antiarch support. According to the failure characteristics of the roadway floor, the U-shaped steel inverted arch support was regarded as a beam that can slide (or rotate) at both ends. The stability conditions and influencing factors of the beam were analyzed by using Fenner's formula and mechanical principle. The causes of floor heave under the support condition were given, and the feasible and effective control scheme was put forward. The method and technology can provide theoretical basis and control measures for the normal use and safe operation of roadway.

\section{Project Overview}

The coal-bearing strata are Yan'an Formation of Jurassic Mesozoic in Liuyuanzi Coal Mine. The coal seams No.4-1 and No.5-1 are divided into upper coal group, and the coal seams No.7-1 and No.8-3 are divided into lower coal group. According to the borehole of No. L503, the track roadway, conveyor roadway, and return air roadway are arranged horizontally at $+1100 \mathrm{~m}$ (i.e., at the lowest point of coal seam No.5-1). The track roadway is buried at a depth of $455 \mathrm{~m}$ and lied in mudstone, fine sandstone, medium sandstone, and sandy mudstone.

The average RQD index of the rock mass is from $39 \%$ to $87 \%$ around the track roadway. The experimental results indicate that the compressive strength of the mudstone in 51 coal seam floor and 7-1 coal seam roof is from 3.94 MPa to 22.2 $\mathrm{MPa}$ in natural state, while it is from $0.16 \mathrm{MPa}$ to 
10.5 $\mathrm{MPa}$ in saturated state, and the softening coefficient is from 0.04 to 0.47 . The characteristics of the rocks are easy to weather, soften, and swell. The original support design of the track roadway in Liuyuanzi Coal Mine is as follows: the boltmesh support is used for the first support, the shotcreting and 36U-shaped steel are used for the second support, shotcreting thickness is $200 \mathrm{~mm}$, the net section is 15.7 square meter, and the driving width and height, respectively, are $4900 \mathrm{~mm}$ and $4500 \mathrm{~mm}$. All these are shown in Figure 1.

\section{Characteristics and Influence Factors of Floor Heave in Roadway}

3.1. Characteristics of Floor Heave in Roadway. According to the on-site investigation, the main characteristics of the floor heave in roadway are as follows:

(1) Large deformation: According to the field investigation, the floor heave of the roadway with mining level $+1100 \mathrm{~m}$ is generally $0.5 \mathrm{~m}$ to $2.2 \mathrm{~m}$. The floor heave can still reach $0.5 \mathrm{~m}$ after the inverted arch support is applied to the local position.

(2) Floor crack: The floor of the roadway is strongly deformed, and floor crack is particularly serious when encountering water.

(3) High deformation speed: According to the on-site measurement, the floor heave speed of the track roadway can reach $10 \mathrm{~mm}$ to $20 \mathrm{~mm} / \mathrm{d}$, which causes floor dinting every month; otherwise it will affect transportation.

\subsection{Factors Affecting Deformation}

3.2.1. Improper Support. Although the antiarch support is applied to track roadway, because of the insufficient rigidity of the contact between the antiarch structure and U-shaped steel support, which leads to the failure of the supporting structure of the floor, floor heave occurs under the action of the floor pressure.

3.2.2. Strata Structure. The track roadway is located near the syncline axis, and the axis of the track roadway is not perpendicular to the syncline axis, so that the track roadway is subjected to a certain level of tectonic stress, forcing the floor rock to extrude into the tunnel, thus causing the extrusion of the antiarch structure and intensifying the floor heave.

3.2.3. Properties and Hydraulic Characteristics of Surrounding Rock. The coal-bearing strata are Yan'an Formation of Jurassic Mesozoic in Liuyuanzi Coal Mine, with well-developed bedding and joints, extremely low strength, easy weathering and fragmentation, easy softening in water, and certain expansibility. Under the influence of Cretaceous aquifer water, the roof water of No. 4 coal, the roof water of No. 5 coal, floor water, and structural water, the water inflow can reach $396.54 \mathrm{~m}^{3} / \mathrm{d}$. The floor mudstone of the track roadway will become muddy and swell when it meets the

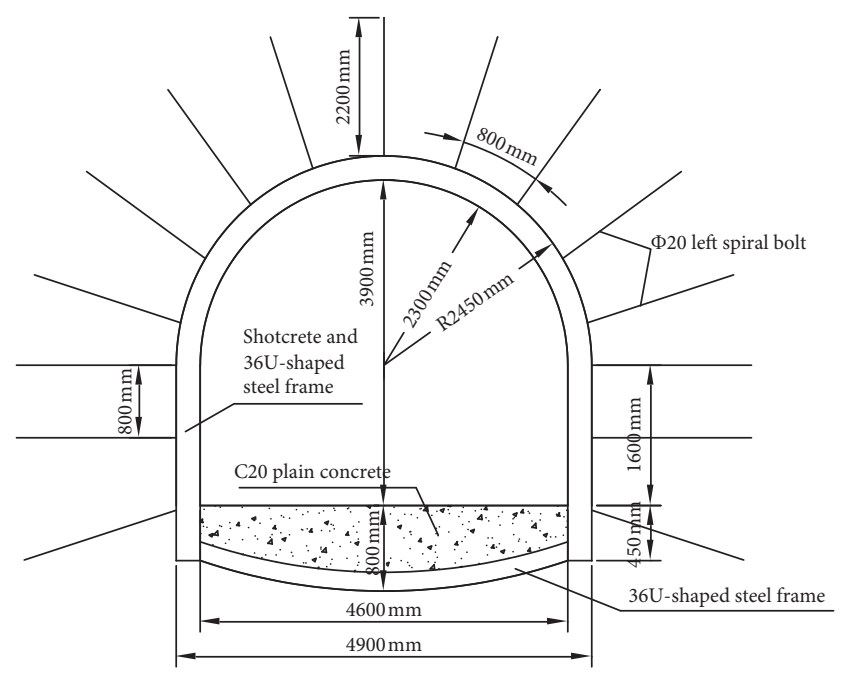

FIgURE 1: Original supporting design of rail roadway.

water, which intensifies the plastic deformation of the floor. This is an important reason for the drastic and long duration of floor heave.

\section{Mechanical Environment and Instability Analysis of the Floor}

4.1. The Stress Field in Roadway. For convenience of the analysis and consideration of engineering practice, the roadway is simplified as the circular hole problem of axisymmetric plane strain in elastic-plastic mechanics in which both the load and the structure are axisymmetric. The mechanical model is shown in Figure 2. $p_{0}$ is original rock stress; $r_{0}$ is roadway radius; $R_{0}$ is plastic zone radius; $p_{s}$ is support strength; this paper refers to the stress acting on surrounding rock of roadway or other supporting structures, which is called the action stress; and $(r, \theta)$ are polar coordinates of any point in plastic zone.

In polar coordinates, according to Fenner's formula and Mohr-Coulomb criterion [33-35], the stress calculation formula of plastic zone of surrounding rock of circular tunnel can be obtained:

$$
\left\{\begin{array}{l}
\sigma_{r}=\left(p_{s}+C \cot \varphi\right)\left(\frac{r}{r_{0}}\right)^{(2 \sin \varphi / 1-\sin \varphi)}-C \cot \varphi, \\
\sigma_{\theta}=\left(p_{s}+C \cot \varphi\right)\left(\frac{r}{r_{0}}\right)^{(2 \sin \varphi / 1-\sin \varphi)} \frac{1+\sin \varphi}{1-\sin \varphi}-C \cot \varphi, \\
\tau_{r \theta}=0,
\end{array}\right.
$$

where $\sigma_{r}$ is radial stress at any point, $\mathrm{MPa} ; \sigma_{\theta}$ is tangential stress at any point, $\mathrm{MPa} ; \tau_{r \theta}$ is shear stress at any point, $\mathrm{MPa}$; $p_{s}$ is the same as the previous one, $\mathrm{MPa}$; $C$ is rock cohesion, $\mathrm{MPa} ; \varphi$ is angle of internal friction for rock, ${ }^{\circ} ; r_{0}$ is radius of roadway, $m$; the rest are as before. 


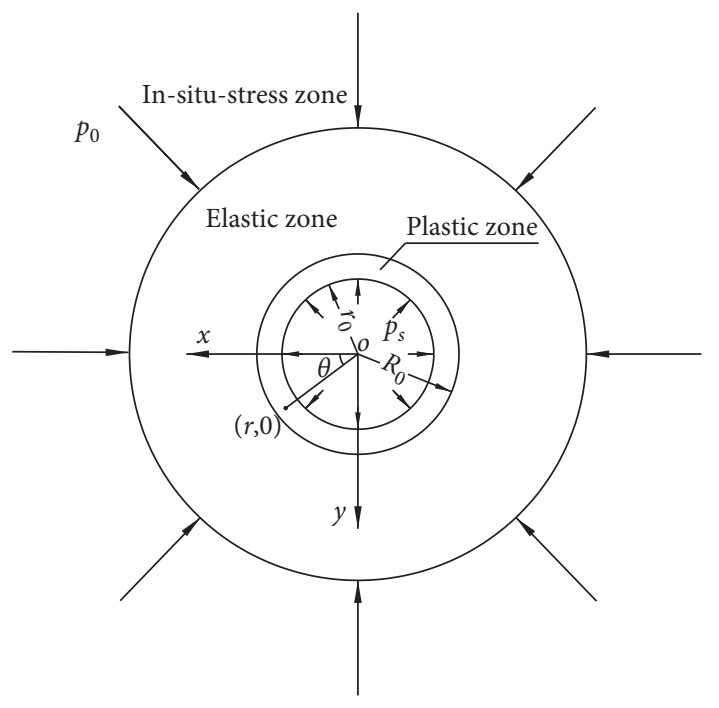

Figure 2: Elastic-plastic zone of circular roadway.

Formula (1) in polar coordinates is transformed into a stress equation in a rectangular coordinate system by means of the following equations:

$$
\left\{\begin{array}{l}
\sigma_{x}=\frac{\sigma_{r}+\sigma_{\theta}}{2}+\frac{\sigma_{r}-\sigma_{\theta}}{2} \cos \theta-\tau_{r \vartheta} \sin 2 \theta, \\
\sigma_{y}=\frac{\sigma_{r}+\sigma_{\theta}}{2}-\frac{\sigma_{r}-\sigma_{\theta}}{2} \cos \theta+\tau_{r \vartheta} \sin 2 \theta, \\
\tau_{x y}=\frac{\sigma_{r}-\sigma_{\theta}}{2} \sin 2 \theta+\tau_{r \vartheta} \cos 2 \theta .
\end{array}\right.
$$

That is,

$$
\left\{\begin{array}{l}
\sigma_{x}=\frac{\sigma_{r}+\sigma_{\theta}}{2}+\frac{\sigma_{r}-\sigma_{\theta}}{2} \cos \theta \\
\sigma_{y}=\frac{\sigma_{r}+\sigma_{\theta}}{2}-\frac{\sigma_{r}-\sigma_{\theta}}{2} \cos \theta \\
\tau_{x y}=\frac{\sigma_{r}-\sigma_{\theta}}{2} \sin 2 \theta .
\end{array}\right.
$$

Substituting (1) into (3), the stress pattern in the Cartesian coordinates near the roadway adjacent to the plastic zone is

$$
\left\{\begin{array}{l}
\sigma_{x}=\left(p_{s}+C \cot \varphi\right)\left(\frac{r}{r_{0}}\right)^{(2 \sin \varphi / 1-\sin \varphi)} \frac{1-\sin \varphi \cos \theta}{1-\sin \varphi}-C \cot \varphi \\
\sigma_{y}=\left(p_{s}+C \cot \varphi\right)\left(\frac{r}{r_{0}}\right)^{(2 \sin \varphi / 1-\sin \varphi)} \frac{1+\sin \varphi \cos \theta}{1-\sin \varphi}-C \cot \varphi \\
\tau_{x y}=-\left(p_{s}+C \cot \varphi\right)\left(\frac{r}{r_{0}}\right)^{(2 \sin \varphi / 1-\sin \varphi)} \frac{\sin \varphi \sin 2 \theta}{1-\sin \varphi}
\end{array}\right.
$$

In general, the shear stress can be neglected when considering the rock mass fracture at the bottom corner of the roadway after excavation. Formula (4) is simplified to

$$
\left\{\begin{array}{l}
\sigma_{x}=\left(p_{s}+C \cot \varphi\right)\left(\frac{r}{r_{0}}\right)^{(2 \sin \varphi / 1-\sin \varphi)} \frac{1-\sin \varphi \cos \theta}{1-\sin \varphi}-C \cot \varphi, \\
\sigma_{y}=\left(p_{s}+C \cot \varphi\right)\left(\frac{r}{r_{0}}\right)^{(2 \sin \varphi / 1-\sin \varphi)} \frac{1+\sin \varphi \cos \theta}{1-\sin \varphi}-C \cot \varphi .
\end{array}\right.
$$

4.2. The Instability of Inverted Arch Structure. The key point to control the floor heave is the joint of U-shaped steel support and inverted arch structure. The friction force is used to ensure the stiffness of the structure. Therefore, the mechanical properties of the joint determine the performance of the whole supporting structure. According to the mechanical behavior of the joint, the floor heave is divided into three types: "sliding upward", "rotating upward," and "sliding-rotating upward," as shown in Figure 3.

(1) "Sliding upward" type: As shown in Figure 3(a), when the floor stress is symmetrically distributed and the friction force between the inverted arch and the U-shaped steel support and its load is insufficient to balance the floor pressure, the inverted arch structure will rise, resulting in the overall uplift of the floor. This type was called "sliding upward" floor heave. Generally, this kind of floor is risen upward on the whole, which is not affected by asymmetric external forces and is not easy to cause floor crack.

(2) "Rotating upward" type: As shown in Figure 3(b), when the stress on the floor is asymmetrically distributed, the floor relatively keeps balance at the narrower end of the concentrated stress zone (called the hinge end), while it will rotate upward around the hinge end at the other end of the concentrated stress zone (called the active end). This type was called "rotating upward" floor heave. Because the floor is subjected to asymmetric external forces after 


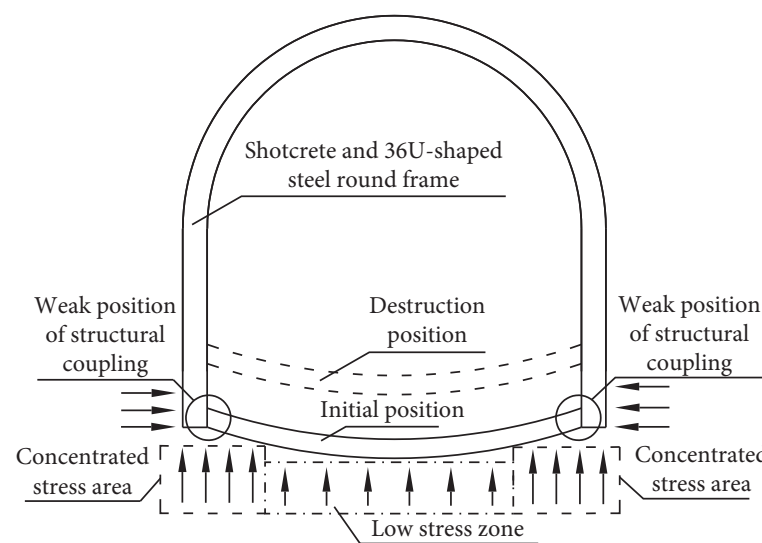

(a)

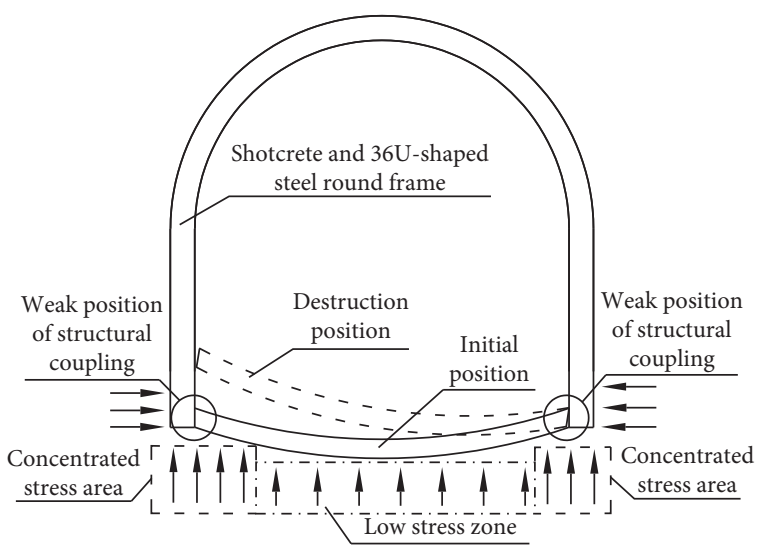

(b)

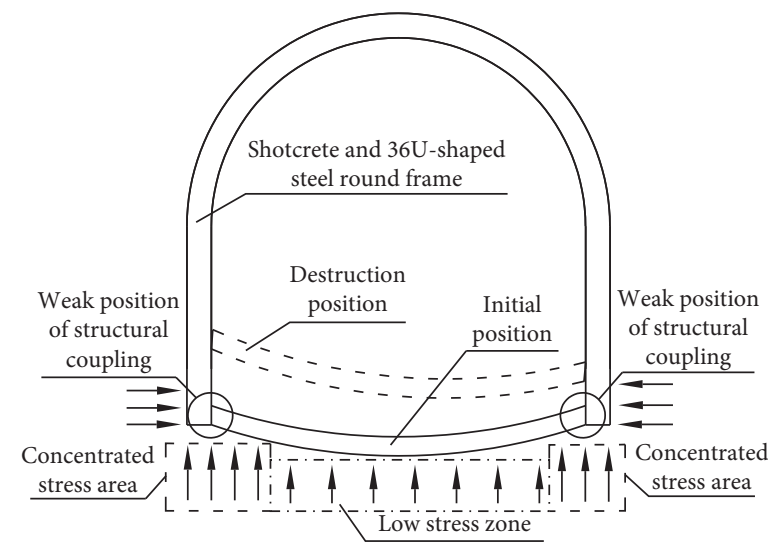

(c)

FIGURE 3: Instability types of inverted arch structures. (a) Sliding upward. (b) Rotating upward. (c) Sliding-rotating upward.

rotation, the bending resistance of concrete is smaller than U-shaped steel, which is easy to cause floor crack.

(3) "Sliding-rotating upward" type: On the one hand, as shown in Figure 3(a), when the inverted arch structure is sliding upward, the stress on the floor may be distributed asymmetrically for some reason, resulting in the change of the floor from sliding upward to rotating upward; on the other hand, as shown in Figure 3(c), when the inverted arch structure is rotating upward, the contact area between the hinged end and the U-shaped steel support decreases, resulting in a great reduction in the frictional force at the joint. The hinge ends cause sliding upward due to mechanical unbalance. All of the above were collectively called "sliding-rotating upward" floor heave. As mentioned earlier, this situation is liable to cause floor crack.

\section{5. "Sliding-Rotating Beam" Model and Its Mechanical Behavior}

5.1. Model of Sliding-Rotating Beam. As shown in Figure 1, the U-shaped steel support strictly limits the transverse displacement of the inverted arch structure, but its longitudinal constraint is relatively weak. At this point, the inverted arch structure can be assumed as a "board." To simplify the analysis, the following assumptions are made for the "board" structure:

(1) The inverted arch and the overlying concrete are a continuous integral structure along the axial direction of the roadway. In order to simplify the calculation, the curved beam is regarded as a straight beam.

(2) The two ends of the "board" are movable supports, which can move up and down but are controlled by friction factors at the contact.

(3) Because of the high bending strength of U-shaped steel antiarch support, the bending of "board" is not considered, and the stress distribution of the floor is consistent with that of Figure 3.

Therefore, the inverted arch structure of the floor can be regarded as a "beam" supported transversely by U-shaped steel at both ends, which is called a "sliding-rotating beam," which can either slide vertically or rotate around an end, as shown in Figure 4(a). The force of "sliding-rotating beam" is shown in Figure 4(b), where $L$ is the length of "slidingrotating beam" and $L=a+b+c, \mathrm{~m} ; a$ and $c$ are the width of concentrated stress action zone, $m ; b$ is the width of low 


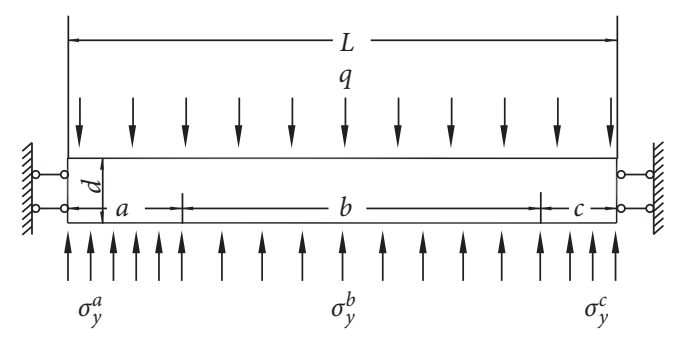

(a)

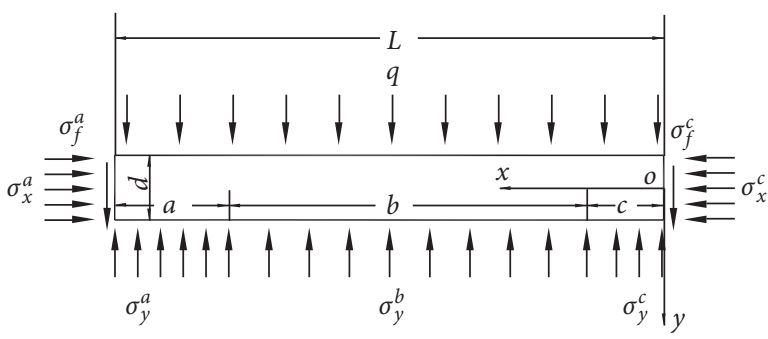

(b)

FIGURE 4: Mechanical model of sliding-rotating beam. (a) Sliding-rotating beam. (b) Force analysis of sliding-rotating beam.

stress action zone, $m ; d$ is the thickness of the beam, $m ; \sigma_{x}^{a}$ and $\sigma_{y}^{a}$ are the concentrated stress of the floor rock on the "sliding-rotating beam" in the width zone equal to " $a$," MPa; $\sigma_{x}^{c}$ and $\sigma_{y}^{c}$ are the concentrated stress of the floor rock on the "sliding-rotating beam" in the width zone equal to " $c$," MPa; $\sigma_{y}^{b}$ is the stress of the floor rock on the "sliding-rotating beam" in the width zone equal to " $b$," $\mathrm{MPa}$; $\sigma_{f}$ is the friction stress of U-shaped steel support and antiarch support, MPa; $q$ is the self-weight stress of concrete overlying inverted arch, $\mathrm{MPa}$.

\subsection{Balance and Motion of "Sliding-Rotating Beam"}

5.2.1. The Equilibrium Condition of "Sliding-Rotating Beam". As shown in Figure 4(b), the "sliding-rotating beam" keeps static balance in the " $x$ " direction, taking the length in units at the direction perpendicular to the " $x o y$ " plane. The static balance of the " $y$ " direction and the moment balance (using " $O$ " as the center of moment) of the "sliding-rotating beam" can be expressed as

$$
\begin{gathered}
\sigma_{y}^{a} a+\sigma_{y}^{b} b+\sigma_{y}^{c} c-\left(\sigma_{f}^{a}+\sigma_{f}^{c}\right) d-q L=0 \\
\sigma_{y}^{a} a\left(L-\frac{a}{2}\right)+\sigma_{y}^{b} b\left(L-\frac{b}{2}-c\right)+\sigma_{y}^{c} c \frac{c}{2}-\sigma_{f}^{a} d L-q L \frac{L}{2}=0
\end{gathered}
$$

where $\sigma_{f}^{a}=f \sigma_{x}^{a} ; \sigma_{f}^{c}=f \sigma_{x}^{c} ; q=\gamma^{\prime} h+p_{s} ; f$ is the equivalent friction factor; $\gamma^{\prime}$ is the body force of concrete, $\mathrm{N} / \mathrm{m}^{3} ; h$ is the thickness of the concrete, $m$; the others are the same as before.

In this paper, the equivalent friction factor is a mechanical parameter to measure the difficulty of reverse arch supporting structure moving to roadway space. The equivalent friction factor here mainly considers the interaction of contact mode (connection mode) between inverted arch structure and roadway wall (or supporting structure). It can be calculated by the ratio of the resistance between the surfaces of a structure or component to the compressive stress applied to the surface. Under the general surface contact and friction conditions, the equivalent friction factor is equal to the static friction coefficient, and its value is less than 1 . The equivalent friction factor will be greater than 1 or even greater if the resistance increasing accessories are set between the reverse arch supporting structure and the $\mathrm{U}$-shaped steel support foot of the roadway. Therefore, the value range of equivalent friction factor in this paper is 0 to $\infty$.

The stress on the "sliding-rotating beam" around the roadway can be calculated according to formula (4); the radius of the roadway in the $a, b$, and $c$ zones of the "slidingrotating beam" is $r_{a}, r_{b}$, and $r_{c}$, respectively.

As shown in Figures 2 and 4(b), replace $p_{s}$ in (5) with $p_{s}+q$; then substituting (5) into (6) and (7), respectively, they can be written as

$$
p_{s}^{L}=\frac{(L-2 f d) K-K\left[(1+\sin \varphi \cos \theta / 1-\sin \varphi)\left[a\left(r_{a} / r_{0}\right)^{k}+b\left(r_{b} / r_{0}\right)^{k}+c\left(r_{c} / r_{0}\right)^{k}\right]-f d(1-\sin \varphi \cos \theta / 1-\sin \varphi)\left[a\left(r_{a} / r_{0}\right)^{k}+c\left(r_{c} / r_{0}\right)^{k}\right]\right]}{(1+\sin \varphi \cos \theta / 1-\sin \varphi)\left[a\left(r_{a} / r_{0}\right)^{k}+b\left(r_{b} / r_{0}\right)^{k}+c\left(r_{c} / r_{0}\right)^{k}\right]-f d(1-\sin \varphi \cos \theta / 1-\sin \varphi)\left[\left(r_{a} / r_{0}\right)^{k}+\left(r_{c} / r_{0}\right)^{k}\right]-L}-\gamma^{\prime},
$$

$$
p_{s}^{R}=\frac{K\left[a(L-(a / 2))+b(L-(b / 2) c)+\left(c^{2} / 2\right)\right]-K\left[(1+\sin \varphi \cos \theta / 1-\sin \varphi)\left[a(L-(a / 2))\left(r_{a} / r_{0}\right)^{k}+b(L-(b / 2)-c)\left(r_{b} / r_{0}\right)^{k}+c^{2} / 2\left(r_{c} / r_{0}\right)^{k}\right]-f d L(1-\sin \varphi \cos \theta / 1-\sin \varphi)\left(r_{a} / r_{0}\right)^{k}\right]-f d L K}{\left[(1+\sin \varphi \cos \theta / 1-\sin \varphi)\left[a(L-(a / 2))\left(r_{a} / r_{0}\right)^{k}+b(L-(b / 2)-c)\left(r_{b} / r_{0}\right)^{k}+c^{2} / 2\left(r_{c} / r_{0}\right)^{k}\right]-f d L(1-\sin \varphi \cos \theta / 1-\sin \varphi)\left(r_{a} / r_{0}\right)^{k}\right]-\left(L^{2} / 2\right)}-
$$

where $p_{s}^{L}$ and $p_{s}^{R}$ are the action stress of the floor when the "sliding-rotating beam" is in critical state of sliding and rotating, which is called critical value, $\mathrm{MPa}$; $k=(2 \sin \varphi / 1-\sin \varphi) ; K=C \cot \varphi$.
In fact, $p_{s}$ is positive. If the result calculated by formula (8) or formula (9) is negative, it means that the roadway floor is in instability state under the current conditions. In conclusion, the condition of "sliding-rotating beam" motion is as follows: 
(1) If $p_{s} \geq p_{s}^{L}$, the floor will maintain balance; otherwise, the "sliding upward" type floor heave will be produced.

(2) If $p_{s} \geq p_{s}^{R}$, the floor will maintain balance; otherwise, the "rotating upward" type floor heave will be produced.

(3) If $p_{s}<p_{s}^{L}$ and $p_{s}<p_{s}^{R}$, the "sliding-rotating upward" type floor heave will be produced.

5.2.2. The Influence of $f$ on $P_{s}$. According to the analysis in Section 4.2, the main reason for the failure of reverse arch support in this paper is the contact relationship and connection mode at the foot of support. Therefore, this section mainly discusses the effect of equivalent friction factor on $p_{s}$.

As shown in Figure 4(b), considering the symmetry distribution of the concentrated stress on both sides of the roadway floor, the thickness of the "sliding-rotating beam" is very small compared with the roadway radius. Let $a=c$, and $r_{a}=r_{b}=r_{c}=r_{0}$; formulas (8) and (9) can be written as

$$
p_{s}^{D}=\frac{2 f d K \sin \varphi(1-\cos \theta)-L K \sin \varphi(1+\cos \theta)}{L \sin \varphi(\cos \theta+1)-2 f d(1-\sin \varphi \cos \theta)}-\gamma^{\prime} h,
$$

where $p_{s}^{D}$ is the action stress of the "sliding-rotating beam" under the condition of symmetrical stress distribution on the floor, also known as the critical value, MPa.

We consider the value of equivalent friction factor when the roadway floor is in the limit of self-stability, that is, when the roadway floor does not need to be supported. Let $p_{s}^{D}=0$ in formula (10); we can get

$$
f=\frac{L \sin \varphi(1+\cos \theta)\left(\gamma^{\prime} h+K\right)}{2 d\left[K \sin \varphi(1-\cos \theta)+\gamma^{\prime} h(1-\sin \varphi \cos \theta)\right]} .
$$

The calculation parameters of track roadway with mining level $+1100 \mathrm{~m}$ in Liuyuanzi Coal Mine are shown in Table 1. By substituting the data in Table 1 into (11), we can draw the relationship between the equivalent friction factor and $p_{s}$, as shown in Figure 5. If the equivalent friction factor can be arbitrarily increased, the equivalent friction coefficient will have a "breaking point value," which divides the $p_{s}-f$ diagram into "meaningless area" and "actual engineering area." When the equivalent friction factor is less than the "breaking point value," that is, $p_{s}$ is negative, it is indicated that the reverse arch support is unstable. Only when the equivalent friction factor is greater than the "breaking point value," $p_{s}$ is positive, it means that the reverse arch support of roadway is likely to be stable. As can be seen from the "actual engineering area" in Figure 5, the relationship between the equivalent friction factor and the action stress of the "sliding-rotating beam" is "class hyperbola." We mainly analyze the "actual engineering area."

It can be seen from Figure 5 that the support of roadway floor is meaningful only when the equivalent friction factor of the roadway support structure exceeds the "breaking point value" of 18.6 under other unchanged conditions. With the increase of the equivalent friction factor, the action stress decreases gradually. This shows that increasing the

\begin{tabular}{|c|c|c|c|c|c|}
\hline Number & Name & Symbol & Value & Unit & Instruction \\
\hline 1 & $\begin{array}{l}\text { Width of } \\
\text { roadway }\end{array}$ & $L$ & 4.6 & $\mathrm{~m}$ & \\
\hline 2 & $\begin{array}{c}\text { Internal } \\
\text { friction angle } \\
\text { of rock mass }\end{array}$ & $\varphi$ & 36 & $\circ$ & \\
\hline 3 & $\begin{array}{c}\text { Rock mass } \\
\text { cohesion }\end{array}$ & C & 0.6 & $\mathrm{MPa}$ & $\begin{array}{c}\text { The softening } \\
\text { coefficient is } \\
0.47\end{array}$ \\
\hline 4 & $\begin{array}{c}\text { Polar } \\
\text { coordinates } \\
\text { of roadway } \\
\text { floor }\end{array}$ & $\theta$ & $-48 \sim 48$ & 。 & $\begin{array}{l}\text { Refer to } \\
\text { Figure } 1 \text { for } \\
\text { calculation }\end{array}$ \\
\hline 5 & $\begin{array}{c}\text { Thickness of } \\
\text { beam }\end{array}$ & $d$ & 0.2 & M & \\
\hline 6 & $\begin{array}{l}\text { Equivalent } \\
\text { friction factor }\end{array}$ & $f$ & 0.15 & & $\begin{array}{l}\text { In this paper, } \\
\text { the value is } \\
\text { equal to the } \\
\text { friction } \\
\text { between steel } \\
\text { and steel }\end{array}$ \\
\hline 7 & $\begin{array}{l}\text { Body force of } \\
\text { concrete }\end{array}$ & $\gamma^{\prime}$ & 0.024 & $\begin{array}{c}\mathrm{MN} / \\
\mathrm{m}^{3}\end{array}$ & $\begin{array}{l}\text { The density is } \\
2400 \mathrm{~kg} / \mathrm{m}^{3}\end{array}$ \\
\hline 8 & $\begin{array}{c}\text { Thickness of } \\
\text { concrete }\end{array}$ & $h$ & 0.5 & $\mathrm{~m}$ & Average value \\
\hline
\end{tabular}

TABLE 1: Calculation parameters.

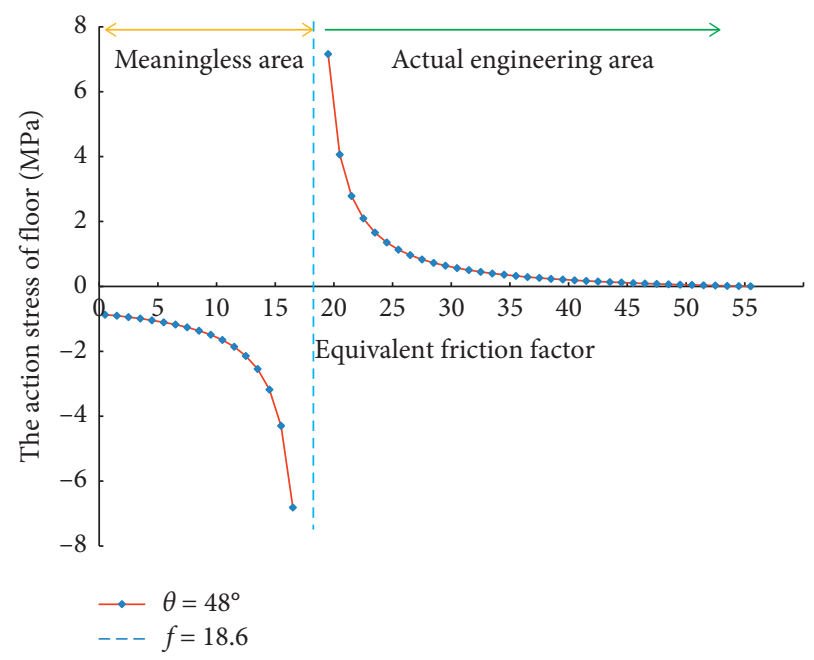

FIGURE 5: Relationship between floor action stress and equivalent friction factor.

equivalent friction factor is helpful to the stability of the reverse arch supporting structure. However, the friction factor of reverse arch support is only 0.15 . Obviously, the floor heave of roadway must occur under this condition.

According to formula (11), the equivalent friction factor of roadway without support is 56.3. This value is far beyond the range of static friction coefficient. This confirmed the inevitability of floor heave once again. In order to increase the equivalent friction factor of the footings, other resistance-increasing accessories or connecting components must be used in the reverse arch support of the mine 
roadway. Of course, if considering the influence of lateral force on the reverse arch support, the resistance-increasing accessories and connecting members are still in an unstable state. Therefore, in this case, the U-shaped steel support with full closure is recommended.

\section{Design and Implementation of Floor Heave Control in Roadway}

6.1. Design of Floor Heave Control in Roadway. Aiming at the original support scheme, bolt-grouting support and inverted arch support were used to repair the roadway for many times, while the floor heave had reached $0.5 \mathrm{~m}$ in three months. At the same time, the maintenance cost increases gradually, which has seriously affected the normal use of track roadway. From the previous theoretical analysis, it can be seen that the floor heave is mainly caused by the insufficient stiffness between the inverted arch and the foot of U-shaped steel support. In order to enhance the support stiffness at the bottom corner of the roadway, 36U-shaped steel round frame with bolt-meshshotcrete-combined support is proposed to control the floor heave. The support design of roadway is shown in Figure 6.

The construction sequence of the support scheme is as follows: firstly, bolt-mesh support is adopted; then $36 \mathrm{U}$ shaped steel round frame is used to support roadway, and finally concrete is poured behind the $36 \mathrm{U}$-shaped steel round frame. The bolt is left-hand thread bolt with a diameter of $20 \mathrm{~mm}$ and a length of $2300 \mathrm{~mm}$. The row spacing between bolts is $900 \mathrm{~mm} \times 900 \mathrm{~mm}$. The Z2335 resin capsule is used as anchoring agent. The metal mesh is welded with concrete irons with diameter of $6 \mathrm{~mm}$, and the mesh size is $80 \mathrm{~mm} \times 80 \mathrm{~mm}$. The diameter of the round frame is $4.6 \mathrm{~m}$, which is composed of six $36 \mathrm{U}$ shaped steel round frames and the overlapping length is $500 \mathrm{~mm}$. The spacing of the round frame is $600 \mathrm{~mm}$. $200 \mathrm{~mm}$ C20 concrete is poured behind the round frame, and $800 \mathrm{~mm}$ thick plain concrete is laid on the bottom of the round frame.

\subsection{Feasibility Analysis of Support Design}

6.2.1. Numerical Model. In order to accurately analyze the feasibility and effectiveness of the new support design, the three-dimensional models of semicircular arch section (original support design) and circular section (new support design) are established and analyzed by FLAC ${ }^{3 \mathrm{D}}$, as shown in Figure 7.

6.2.2. Computing Mode and Parameters. To accurately analyze the problem, combining with the surrounding rock environment of the roadway to restore the actual roadway engineering, Mohr-Coulomb strength criterion, IsotropicFluid-Flow constitutive model, and Fluid-Mechanical Interaction calculation model are used in the models. The physical and mechanical parameters used in the calculation are shown in Table 2. The bolts and the U-shaped steel

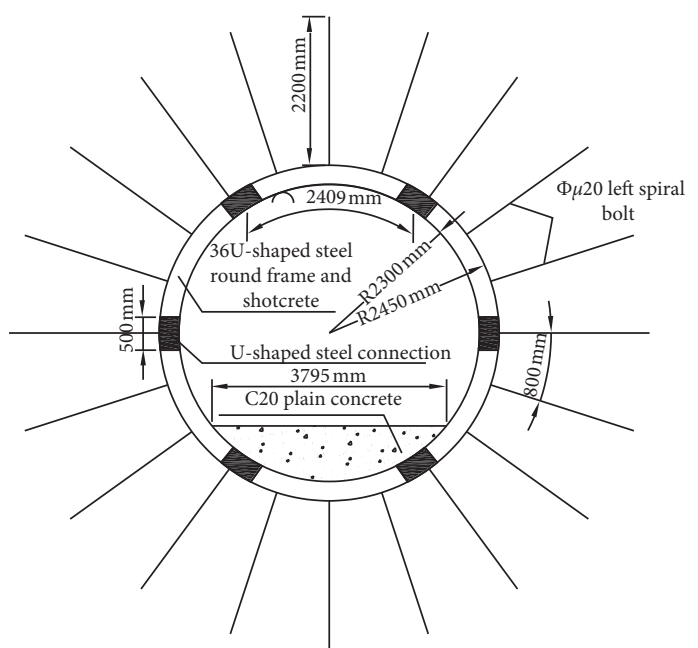

FIGURE 6: The floor bolt-mesh-shotcrete and 36U-shaped steel round frame combined support design.

supports are generated by cable units and shell units, respectively. The specific mechanical parameters are shown in Tables 3 and 4.

6.3. Simulation Results. As shown in Figure 8, when excavating $6 \mathrm{~m}$, the floor stress of the semicircular arch roadway shifts to the bottom corner, the compressive stress is $8.7 \mathrm{MPa}$, and the center zone of the floor bears tensile stress for about $0.6 \mathrm{MPa}$, and the former is 14.5 times of the latter. The floor stress of the circular roadway shifts to the two sides of the rock mass, the compressive stress is $7.0 \mathrm{MPa}$, and the center zone of the floor bears compressive stress for about $2.0 \mathrm{MPa}$, and the former is 3.5 times of the latter. So the circular section roadway support scheme may change the floor from tension to compression. Moreover, to a certain extent, it can homogenize the stress distribution of the floor, which is conducive to the stability of the floor.

As shown in Figure 9, the plastic depths of floor of semicircular arch tunnel and circular tunnel are $2.5 \mathrm{~m}$ and $1.0 \mathrm{~m}$, respectively, when excavating $6 \mathrm{~m}$, while the latter is only $40 \%$ of the former, which shows that the circular section roadway support scheme can effectively restrain the plastic expansion of the floor.

As shown in Figure 10, the floor displacements of semicircular arch roadway and circular roadway are $12.3 \mathrm{~mm}$ and $7.8 \mathrm{~mm}$, respectively, and the latter is only $63 \%$ of the former when excavating $6 \mathrm{~m}$. Thus, circular roadway support scheme can effectively control floor heave.

By the above analysis, 36U-shaped steel round frame with bolt-mesh-shotcrete-combined support is feasible and reliable. After the implementation of the scheme, the roadway waistline is demarcated again, and the roadway floor heave is calculated based on it. After two months of monitoring, the floor heave of roadway is reduced from $246 \mathrm{~mm}$ to $76 \mathrm{~mm}$, and the floor heave is reduced by $69.1 \%$. 


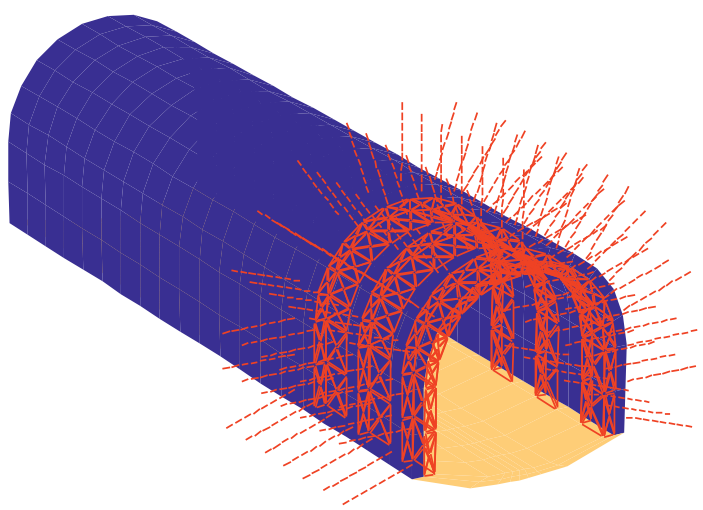

(a)

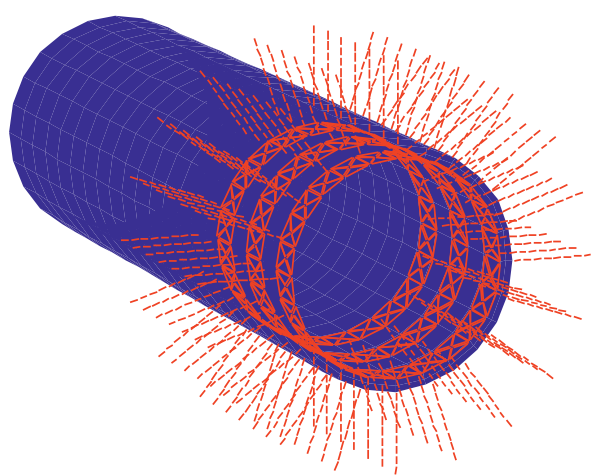

(b)

Figure 7: Mechanical model and supporting structure of semicircular arch and circle arch rail roadway.

TABLE 2: Mechanical parameters for surrounding rock and coal.

\begin{tabular}{lccccccc}
\hline Number & Name & $\gamma\left(\mathrm{MN} / \mathrm{m}^{3}\right)$ & $E(\mathrm{MPa})$ & $v$ & $\sigma_{\mathrm{t}}(\mathrm{MPa})$ & $C(\mathrm{MPa})$ & $\Phi\left(^{\circ}\right)$ \\
\hline 1 & Mudstone & 0.0257 & 4800 & 0.32 & 1.05 & 0.6 & 36 \\
2 & Fine sandstone & 0.0291 & 28840 & 0.18 & 4.75 & 3.38 \\
3 & Medium-grained sandstone & 0.026 & 6800 & 0.26 & 2.3 & 42 \\
4 & Coal & 0.0142 & 2410 & 0.29 & 0.36 & 3.7 \\
5 & Concrete & 0.023 & 25500 & 0.2 & 1.6 & 34 \\
\hline
\end{tabular}

TABLE 3: Parameters for bolt simulation.

\begin{tabular}{lccccc}
\hline $\begin{array}{l}\text { Elastic modulus } \\
(\mathrm{GPa})\end{array}$ & $\begin{array}{c}\text { Cohesion of cement } \\
\text { paste on unit length } \\
\left(\mathrm{kN} \cdot \mathrm{m}^{-1}\right)\end{array}$ & $\begin{array}{c}\text { Shear stiffness of } \\
\text { cement } \\
\text { paste on unit length } \\
\left(\mathrm{MN} \cdot \mathrm{m}^{-2}\right)\end{array}$ & $\begin{array}{c}\text { Outer perimeter } \\
\text { of cement paste } \\
(\mathrm{mm})\end{array}$ & $\begin{array}{c}\text { Cross-sectional area } \\
\left(\mathrm{mm}^{2}\right)\end{array}$ & $\begin{array}{c}\text { Prestress } \\
(\mathrm{kN})\end{array}$ \\
\hline 205 & 266 & 95000 & 61.8 & 314 & 60 \\
\hline
\end{tabular}

TABle 4: Parameters for U-type steel.

\begin{tabular}{lccc}
\hline Elastic modulus $(\mathrm{GPa})$ & Poisson ratio & Density $\left(\mathrm{kg} \cdot \mathrm{m}^{-3}\right)$ & Thickness $(\mathrm{m})$ \\
\hline 206 & 0.26 & 7500 & 0.2 \\
\hline
\end{tabular}

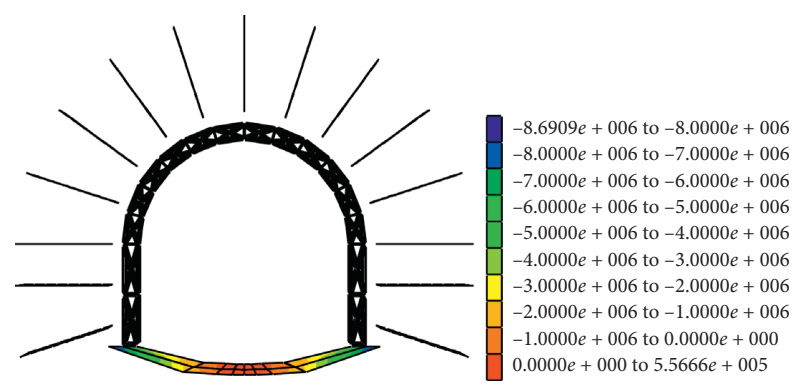

(a)

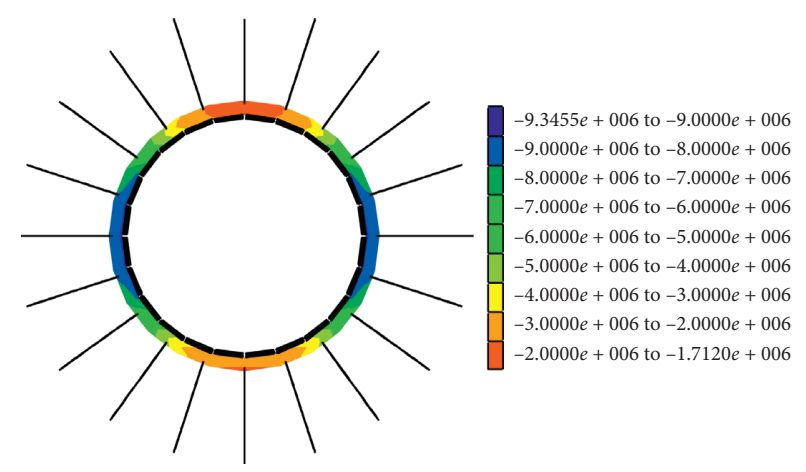

(b)

FIgURE 8: Floor stress contours of roadway in excavation of $6 \mathrm{~m}$. (a) Semicircular arch roadway. (b) Circle roadway. 


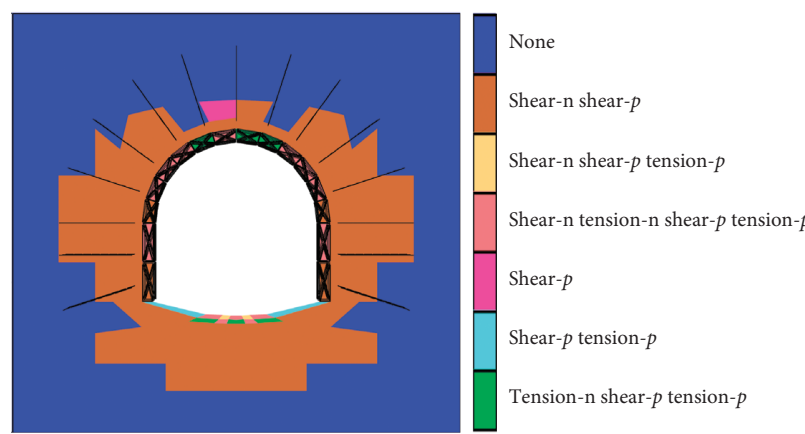

(a)

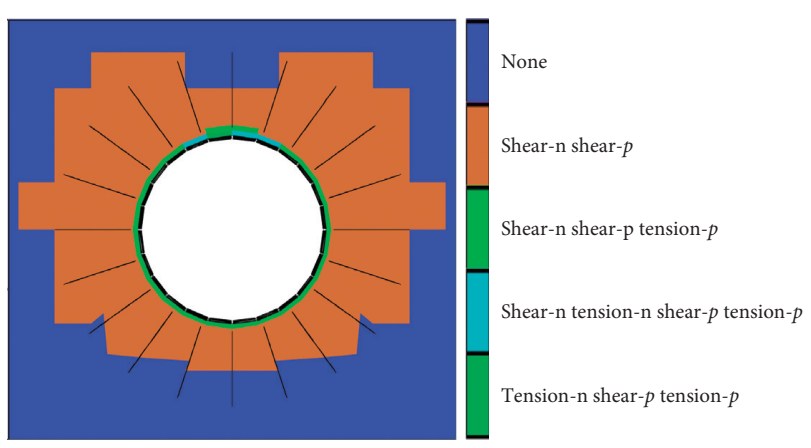

(b)

FIgURE 9: Yield zone distribution of roadway in excavation of $6 \mathrm{~m}$. (a) Semicircular arch roadway. (b) Circle roadway.

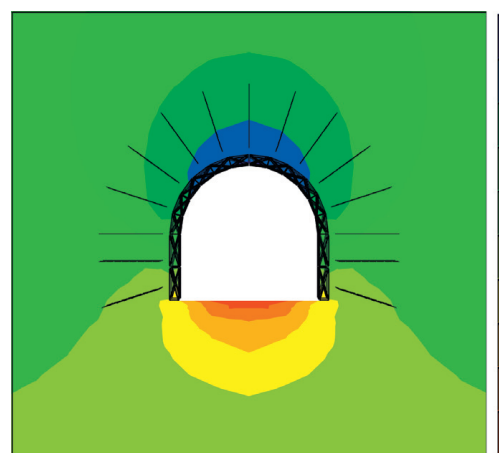

(a)

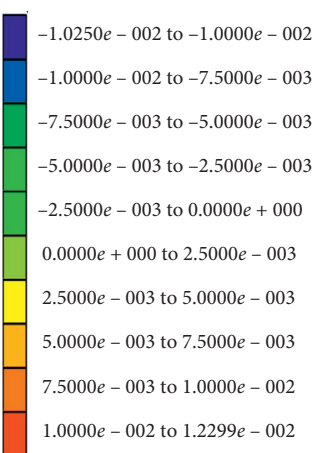

$.0000 e-002$ to $1.2299 e-002$

Figure 10: Displacement contours of roadway in excavation of $6 \mathrm{~m}$. (a) Semicircular arch roadway. (b) Circle roadway.

\section{Conclusion}

(1) Insufficient strength of the connections between U-shaped steel and inverted arch structure is the key to instability, and the roadway is located in the lower part of synclinal structure coal seam, the floor rock mass is broken, and the floor heave is aggravated by water softening.

(2) The mechanical model of "sliding-rotating beam" is proposed for the instability of the inverted arch floor structure, and the equilibrium equation of the "sliding-rotating beam" is deduced. If $p_{s} \geq p_{s}^{i}(i=L, R, D)$, "sliding-rotating beam" will keep stability. If $p_{s}<p_{s}^{i}(i=L, R, D)$, three instability modes will occur in the "sliding-rotating beam": "sliding upward," "rotating upward," and "slidingrotating upward." Under normal conditions, the critical value calculation formulas of the three modes can be simplified into one formula.

(3) The equivalent friction factor affects the stability of reverse arch supporting structure. By increasing the equivalent friction factor between the inverted arch structure and the U-shaped steel support, the "sliding-rotating beam" can keep balance, but the equivalent friction factor has a "breaking point value"; when the equivalent friction factor is less

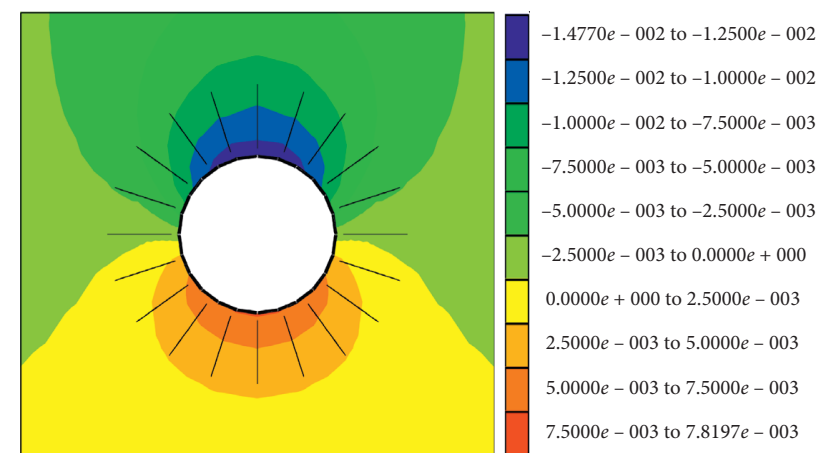

(b) than the "breaking point value," the "sliding-rotating beam" cannot keep balance, and the floor heave must occur. If the equivalent friction factor is greater than the "breaking point value," then a sufficiently large equivalent friction factor can keep the "sliding-rotating beam" stable. The "breaking point value" of the foot of reverse arch support is 18.6, which is much larger than the one of the reverse arch supporting structure. So the floor heave must happen.

(4) The 36U-shaped steel round frame with bolt-meshshotcrete-combined support is applied to improve the coupling relationship of bottom corner support. After the implementation of the scheme, the results show that the floor heave is reduced by $69.1 \%$. Therefore, the fully closed yieldable metal support is more suitable for roadway floor heave control.

\section{Data Availability}

The data used to support the findings of this study are available from the corresponding author upon request.

\section{Conflicts of Interest}

The authors declare that they have no conflicts of interest. 


\section{Acknowledgments}

This work was supported by the National Natural Science Foundation of China (Grant no. 51964037) and the Key Projects of the National Natural Science Foundation of China (Grant no. 51634007).

\section{References}

[1] H. P. Xie, H. W. Zhou, J. D. Xue et al., "Research and consideration on deep coal mining and critical mining depth," Journal of China Coal Society, vol. 37, no. 4, pp. 535-542, 2012.

[2] P. Kyle, B. Joel, K. Unrug, and M. Klimek, "Mitigation of floor heave in West Kentucky coal mine," International Journal of Mining Science and Technology, vol. 26, no. 3, pp. 521-525, 2016.

[3] S. M. Hsiung and S. S. Peng, "Control of floor heave with proper mine design-three case studies," Mining Science and Technology, vol. 4, no. 3, pp. 257-272, 1987.

[4] A. Royanfar and K. Shahriar, "Investigation of factors affecting floor heave and convergence of galleries in Tabas coal mine," ", in Proceedings of the 20th International Mining Congress and Exhibition of Turkey, IMCET, pp. 41-46, Ankara, Turkey, June 2007.

[5] H. Maleki, C. Stewart, R. Stone, J. Abshire, and J. Whyatt, "Analysis of sudden floor heave in deep western U. S. mines," in Proceedings of the SME Annual Meeting and Exhibit and CMA's 111th National Western Mining Conference, pp. 54-62, Denver, CO, USA, February 2009.

[6] J. C. Stankus and S. S. Peng, "Floor bolting for control of mine floor heave," Mining Engineering, vol. 46, no. 9, pp. 10991102, 1994.

[7] K. Haramy and J. McDonnell, "Floor heave analysis in a deep coal mine," in Proceedings of the Symposium on Rock Mechanics, pp. 520-525, Berkeley CA, USA, August 1986.

[8] Y. Xu, E. Zhang, Y. Luo, L. Zhao, and K. Yi, "Mechanism of water inrush and controlling techniques for fault-traversing roadways with floor heave above highly confined aquifers," Mine Water and the Environment, vol. 39, no. 2, pp. 320-330, 2020.

[9] R. Sabapathy, P. S. Paul, and P. K. Mandal, "Evaluation of bump-proneness of underground coal mines using burst energy coefficient," Arabian Journal of Geosciences, vol. 12, no. 18 , pp. 1-16, 2019.

[10] T. T. Ozan and S. Budavari, "Study of floor heave in two South African collieries under different conditions," in Proceedings of the 4th Annual IEEE Conference on Visualization, p. 465, San Jose, CA, USA, October 1993.

[11] S. S. Peng, Coal Mine Ground Control, West Virginia University, Morgantown, West Virginia, 3 edition, 2008.

[12] S. Richard and P. Konečný, "Stability of roadways in coalmines alias rock mechanics in practice," Journal of Rock Mechanics and Geotechnical Engineering, vol. 2, no. 3, pp. 281-288, 2010.

[13] W. Abdellah, "Numerical modelling stability analyses of haulage drift in deep underground mines," The Journal of Engineering Sciences, Assiut University, vol. 43, no. 1, pp. 71-81, 2015.

[14] C. Faria Santos and Z. T. Bieniawski, "Floor design in underground coal mines," Rock Mechanics and Rock Engineering, vol. 22, no. 4, pp. 249-271, 1989.

[15] S. Mo, H. L. Ramandi, J. Oh et al., "A Review of floor heave mechanisms in underground coal mine roadways," in
Proceedings of the Fourth Australasian Ground Control in Mining Conference, pp. 196-206, Sydney, Australia, November 2018.

[16] P. Sheffield and P. Corbett, "Managing floor heave in an underground longwall coal mine," in Proceedings of the Fourth Australasian Ground Control in Mining Conference, pp. 78-94, Sydney, Australia, November 2018.

[17] M. A. Van Dyke, M. M. Sears, T. M. Klemetti, D. W. H. Su, I. B. Tulu, and J. Wickline, "Geological evaluation of floor heave in a longwall mine under deep overburden," in Proceedings of the 52nd US Rock Mechanics/Geomechanics Symposium, Seattle, WA, USA, June 2018.

[18] B. A. Slaker, M. M. Murphy, and T. Miller, "Analysis of monitoring techniques to measure floor heave in an underground limestone mine," in Proceedings of the SME Annual Conference and Expo 2017, pp. 54-58, Denver, CO, USA, February 2017.

[19] H. P. Kang, Mechanism and Prevention of Soft Rock Roadway Floor Heave, Coal Industry Press, Beijing, China, 1993.

[20] A. Kidybiński, "Design criteria for roadway supports to resist dynamic loads," International Journal of Mining and Geological Engineering, vol. 4, pp. 91-109, 1986.

[21] Vasundhara, Geomechanical behaviour of soft floor strata in underground coal mines, $\mathrm{PhD}$ thesis, University of New South Wales, Sydney, Australia, 1999.

[22] S. Mo, K. Tutuk, and S. Sayadam, "Management of floor heave at Bulga underground Operations-A case study," International Journal of Mining Science and Technology, vol. 29, pp. 73-78, 2019.

[23] P. Malkowski and L. Ostrowski, "Convergence monitoring as a basis for numerical analysis of changes of rock-mass quality and hoek-brown failure criterion parameters due to longwall excavation," Archives of Mining Sciences, vol. 64, no. 1, pp. 93-118, 2019.

[24] S. Mo, H. L. Ramandi, J. Oh et al., "A new coal mine floor rating system and its application to assess the potential of floor heave," International Journal of Rock Mechanics and Mining Sciences, vol. 128, pp. 1-6, Article ID 104241, 2020.

[25] X. P. Lai, H. C. Xu, P. F. Shan, Y. L. Kang, Z. Y. Wang, and $\mathrm{X}$. Wu, "Research on mechanism and control of floor heave of mining-influenced roadway in top coal caving working face," Energies, vol. 13, no. 2, pp. 1-14, 2020.

[26] H. S. Jia, L. Y. Wang, K. Fan, B. Peng, and K. Pan, "Control technology of soft rock floor in mining roadway with coal pillar protection: A case study," Energies, vol. 12, no. 15, pp. 1-21, 2019.

[27] Z. Zhang, J. Bai, Y. Chen, and S. Yan, "An innovative approach for gob-side entry retaining in highly gassy fullymechanized longwall top-coal caving," International Journal of Rock Mechanics and Mining Sciences, vol. 80, no. 1, pp. 1-11, 2015.

[28] H. Kang, J. Lou, F. Gao, J. Yang, and J. Li, "A physical and numerical investigation of sudden massive roof collapse during longwall coal retreat mining," International Journal of Coal Geology, vol. 188, no. 1, pp. 25-36, 2018.

[29] D. D. Qin, X. F. Wang, D. S. Zhang, and X. Y. Chen, "Study on surrounding rock-bearing structure and associated control mechanism of deep soft rock roadway under dynamic pressure," Sustainability, vol. 11, no. 7, pp. 1-15, 2019.

[30] W.-q. Peng, W.-j. Wang, and C. Yuan, "Supporting technology research in deep well based on modified Terzaghi formula," Advances in Civil Engineering, vol. 2018, pp. 1-6, Article ID 9483538, 2018. 
[31] S. Shreedharan and P. H. S. W. Kulatilake, "Discontinuumequivalent continuum analysis of the stability of tunnels in a deep coal mine using the distinct element method," Rock Mechanics and Rock Engineering, vol. 49, no. 5, pp. 1903-1922, 2016.

[32] C. X. Chun, L. Wang, Z. H. Liu, and X. L. Zhang, "Application and mechanism to support tunnel adjoining with soft rock masses by yielding inverted arch of composite structures," Applied Mechanics and Materials, vol. 90-93, pp. 791-794, 2011.

[33] R. Fenner, "Untersuchungen zur erkenntnis des gebirgsdruckes," Glückauf, vol. 74, pp. 681-695, 1938.

[34] C. A. Coulomb, "Sur une application des r6gles de maximis et minimis a quelques probl6mes de tatique relatifs g l' architecture," Academie Royaldes Sciences Memoires de mathematique et de physique par divers savans, vol. 7, pp. 343-382, 1773.

[35] A. L. Florence and L. E. Schwer, "Axisymmetric compression of a Mohr-Coulomb medium around a circular hole," International Journal for Numerical and Analytical Methods in Geomechanics, vol. 2, no. 4, pp. 367-379, 1978. 